\title{
Progression of coronary atherosclerotic plaque burden and relationship with adverse cardiovascular event in asymptomatic diabetic patients
}

Junjie Yang ${ }^{1,2,3}$, Guanhua Dou' ${ }^{1}$, Christian Tesche ${ }^{3,4}$, Carlo N. De Cecco ${ }^{3}$, Brian E. Jacobs ${ }^{3}$, U. Joseph Schoepf ${ }^{3}$ and Yundai Chen ${ }^{1 *}$ (1)

\begin{abstract}
Background: The heterogeneity of risk in patients with diabetes mellitus (DM) is acknowledged in new guidelines promulgating different treatment recommendations for diabetics at low cardiac risk. We performed a retrospective longitudinal follow-up study to evaluate coronary plaque progression and its impact on cardiac events in asymptomatic diabetic patients.

Methods: Data of 197 asymptomatic patients (63.1 \pm 17 years, 60\% males) with DM and suspected coronary artery disease (CAD) who underwent clinically indicated dual-source cardiac computed tomography (CT) were retrospectively analyzed. Patients with DM received standard of care treatment. Patients were classified into two groups based on $C T$ coronary artery calcium scores (CACS): A, CACS > 10; B, CACS $\leq 10$. Progression of coronary plaque burden in both groups was evaluated and compared by baseline and follow-up coronary $C T$ angiography (CCTA) using semi-automated plaque analysis and quantification software. Follow-up data were retrospectively gathered from medical records and endpoints of cardiac events were recorded via prospective phone-calls. The impacts of plaque composition and progression on cardiac events were specifically assessed.
\end{abstract}

Results: Patients with CACS> 10 showed an increase in dense coronary calcium volume, while patients with CACS $\leq 10$ had a more pronounced increase in the volume of low-attenuation "lipid-rich" plaque components between CCTA acquisitions. The composite endpoint occurred in 20 patients (10.2\%) after a median follow-up period of 41.8 months. Furthermore, at follow-up CCTA, the presence of CACS> 10 (adjusted odds ratio, 0.701; 95\% Cl, 0.612-0.836), increase of dense calcium volume (OR, $0.86095 \% \mathrm{Cl}, 0.771-0.960)$, and lipid volume $(\mathrm{OR}, 1.013 ; 95 \% \mathrm{Cl}, 1.007-1.020)$ were all independent predictors of cardiac events.

Conclusion: Asymptomatic patients with DM experienced plaque progression as well as progression to "overt or silent CAD". The relative increase in plaque volume was associated with subsequent cardiac events, and the coronary calcification seemed to be inversely related to the outcome in asymptomatic diabetic patients.

Keywords: Coronary artery disease, Type 2 diabetes, Coronary computed tomography angiography, Plaque progression, Outcome

\footnotetext{
* Correspondence: cyundai301@sina.com

'Department of Cardiology, Chinese PLA General Hospital, Beijing, People's

Republic of China

Full list of author information is available at the end of the article
}

(c) The Author(s). 2019 Open Access This article is distributed under the terms of the Creative Commons Attribution 4.0 International License (http://creativecommons.org/licenses/by/4.0/), which permits unrestricted use, distribution, and reproduction in any medium, provided you give appropriate credit to the original author(s) and the source, provide a link to the Creative Commons license, and indicate if changes were made. The Creative Commons Public Domain Dedication waiver (http://creativecommons.org/publicdomain/zero/1.0/) applies to the data made available in this article, unless otherwise stated. 


\section{Highlights}

- Serial non-invasive CCTA enables quantification of atherosclerotic plaque progression in asymptomatic diabetic patients.

- Changes in low attenuation atheroma volume as an imaging biomarker of vulnerable plaque may help to identify patients at risk.

- Higher levels of atherosclerotic calcification may have protective value on plaque stabilization.

\section{Background}

Diabetes mellitus (DM) has been widely considered a coronary artery disease (CAD) equivalent, which implies a 10 -year cardiovascular risk of $20 \%$ for every diabetic patient [1]; however, recently published data refute this notion [2,3]. According to medical convention, patients with $\mathrm{DM}$ are at a higher risk for developing CAD, despite lacking any pertinent symptoms [4]. Thus, it remains controversial whether asymptomatic diabetic patients should be screened for CAD and receive early optimized medical therapy even there is low coronary calcium score $[5,6]$.Previous studies have demonstrated that diabetic patients with initially asymptomatic CAD show accelerated plaque progression, despite the use of optimized medical treatment. Eventually, patients with DM develop more major adverse cardiac events (MACE) and evidence of permanent myocardial injury than patients without $[7,8]$. Recent studies have highlighted the incremental increase in event rates associated with coronary artery calcification [9]. These investigations showed significantly more adverse outcomes in diabetic patients with a computed tomographic (CT) coronary artery calcium score (CACS) $\geq 10$ than in patients without DM [10]. Thus, effective screening strategies for appropriate cardiovascular risk stratification of asymptomatic diabetic patients warrant further study.

Coronary CT angiography (CCTA) allows for the direct quantification and characterization of atherosclerotic plaque for potential risk evaluation beyond the assessment of stenosis [11-13]. Furthermore, CCTA enables serial non-invasive monitoring of plaque progression [14-16] and therefore may help to identify patients at risk for future adverse cardiovascular events $[17,18]$.

The aim of the present study was to monitor the progression of the atherosclerotic coronary plaque burden by serial cardiac CT and evaluate its relationship with cardiac events in asymptomatic diabetic patients.

\section{Methods}

\section{Study population}

This study was approved by the Institutional Review Board of Chinese PLA general hospital with a waiver of informed consent due to the retrospective nature of this investigation. The authors had full control of the data and the information submitted for publication. We consecutively included asymptomatic patients who were referred to our hospital for evaluation and underwent serial CCTA between October 2011 and December 2015 as part of their clinical work-up for the evaluation of CAD.

Among all CCTA scans performed within the dedicated time period, 225 patients matched the following inclusion criteria: (1) a prior CCTA study performed at our institution during the study period that had identified no obstructive (i.e., $\geq 50 \%$ coronary stenosis) CAD; (2) no known history of obstructive CAD or an infectious/inflammatory cardiovascular condition (e.g., aortitis, Kawasaki disease); (3) diagnosis of DM including (a) men $\geq 50$ years or women $\geq 55$ years with $\geq 3$ years history of DM (b) men $\geq 40$ years or women $\geq 45$ years with $\geq 6$ years history of DM. Patients were classified into two groups based on CACS to reflect their cardiovascular risk: group A, CACS $>10$ (high risk); group $\mathrm{B}, \mathrm{CACS} \leq 10$ (low risk) [19]. Exclusion criteria were symptomatic cerebral vascular disease or symptomatic peripheral vascular disease, known history of obstructive CAD with $\geq 50 \%$ coronary stenosis and/or prior coronary revascularization. Patient baseline characteristics including cardiac risk factors and clinical parameters were obtained from medical records.

\section{CCTA acquisition}

All CCTA examinations were performed using a 2nd generation dual-source CT (DSCT) system (Somatom Definition Flash, Siemens Healthineers, Forchheim, Germany). For coronary artery calcium scoring, a non-contrast enhanced calcium scan was performed with the following parameters: collimation of $32 \times 1.2 \mathrm{~mm} ; 120 \mathrm{kVp}$ tube voltage; tube current of $75 \mathrm{~mA}$; 3 -mm slice thickness with 1.5 $\mathrm{mm}$ increment. Scan parameters for the subsequent contrast enhanced CCTA were as follows: collimation of 2 $\mathrm{mm} \times 64 \mathrm{~mm} \times 0.6 \mathrm{~mm}, \mathrm{z}$-axis flying focus technique and a gantry rotation of $280 \mathrm{~ms}$. Patients with a body mass index (BMI) $\geq 26 \mathrm{~kg} / \mathrm{m}^{2}$ were examined with a tube voltage of $120 \mathrm{kVp}$, whereas patients with a BMI $<26 \mathrm{~kg} / \mathrm{m}^{2}$ were examined with a tube voltage of $100 \mathrm{kVp}$. Each tube provided a maximum of $430 \mathrm{mAs} /$ rotation. Weighted filtered back projection image reconstruction was performed in the cardiac phase with the least motion and the following parameters: section thickness of $0.75 \mathrm{~mm}$, reconstruction increment of $0.5 \mathrm{~mm}$ and a smooth convolution kernel (B26f).

\section{Analysis of CCTA data and quantitative plaque assessment}

CCTA data were transferred to a post-processing workstation (syngo.via VA30, Siemens Healthineers) for further analysis. Transverse sections and automatically generated curved multi planar reformations were available for 
assessment. CCTA data were analyzed in consensus by two experienced observers according to CAD reporting and data system (CAD-RADS) [20]. Each segment was assessed for interpretability. Segments were defined as uninterpretable in the presence of severe motion artefacts or low contrast opacification. Additionally, segments with a diameter $<2 \mathrm{~mm}$ were excluded from further analysis [7].

A dedicated semi-automatic software prototype (Coronary Plaque Analysis 2.0.3 syngo.via FRONTIER, Siemens) was used for the quantitative plaque analysis. This analytical software uses automated segmentation based on attenuation values in Hounsfield Units (HU) specific to the target anatomy within user-defined proximal and distal boundaries to compute quantitative atherosclerotic lesion descriptors. All automated contouring of the external vessel wall and internal lumen was reviewed on the basis of $0.5 \mathrm{~mm}$ sections. Manual contouring of the centerline, lumen, and vessel wall boundary was performed in case the automated segmentation provided by the software deviated from the correct vessel boundaries. Plaque volume was calculated by subtracting the lumen volume from the total vessel volume (Fig. 1). Plaque volumes were then normalized by coronary artery length to determine the plaque volume index (PVI, in $\mathrm{mm}^{2}$ ). Plaque subtypes have previously been defined as "soft", "lipid-rich" plaque $(-100 \mathrm{HU}-30 \mathrm{HU})$, "fibrous" plaque $(>30 \mathrm{HU}-350 \mathrm{HU})$, and "calcified" plaque ( $>350 \mathrm{HU}-1300 \mathrm{HU})$ and expressed as a percentage of overall plaque volume to generate the soft-, fibrous-, and calcified plaque fraction (in \%).

"Vulnerable" plaques were defined as exhibiting at least 2 of the following 4 imaging biomarkers: 1) Positive remodeling above $10 \%$ calculated by the ratio of lesion diameter to a proximal reference diameter in a normal vessel segment. 2) Low attenuation, defined by having a mean attenuation $<150 \mathrm{HU}$ in the plaque. 3) Spotty calcifications, defined as calcified nodules $<3 \mathrm{~mm}$ in size and not occupying more than 90 degrees of the coronary arc. 4) "Napkin-ring" sign, defined as a cross section with non-calcified plaque with a ring-like higher attenuation pattern surrounding a central area of lower attenuation in contact with the coronary lumen.

\section{Follow-up assessment}

Follow-up data were prospectively gathered via phone-call between December 2017 and February 2018 by an independent investigator blinded to initial CCTA results. Medical records from both the department of cardiology and the referring outpatient diabetic clinic were analyzed. Three endpoints were recorded: 1. all-cause mortality, 2 . non-fatal myocardial infarction, 3. revascularization. Nonfatal myocardial infarction was defined based on the criteria of typical chest pain, elevated cardiac enzyme levels, and changes on electrocardiogram that are typically associated with infarction. Revascularization was defined as receiving percutaneous coronary intervention or coronary artery bypass grafting after CCTA acquisition. A composite endpoint was constructed from all three endpoints for the analysis.

\section{Statistical analysis}

Statistical analysis was performed using SPSS (SPSS 19.0, IBM, Chicago, USA). Continuous variables were expressed as mean $\pm \mathrm{SD}$, and discrete variables as absolute numbers and percentages. Student's t-tests was used to evaluate

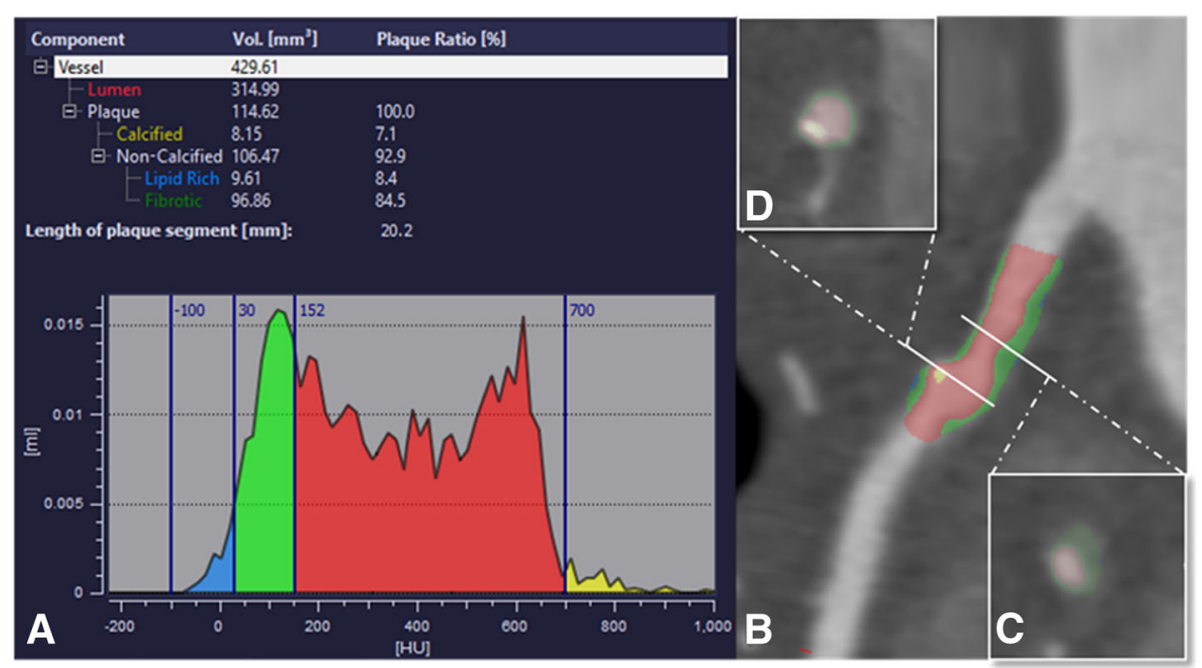

Fig. 1 Coronary plaque analysis from computed tomography coronary angiography. To obtain quantitative and qualitative patient-specific plaque markers, the plaque burden is analyzed according to tissue attenuation based on Hounsfield Units (a). Example of the longitudinal tracking by an automatically generated curved multiplanar image data reformation along the vessel centerline (b) and corresponding transverse luminal sections perpendicular to the centerline (c and $\mathbf{d}$ ) provided by the software 
differences in continuous variables between the two groups. A chi-squared test or Fisher's exact test was used to test differences concerning categorical data and the Wilcoxon rank-sum test was used for non-normally distributed variables. MACE and their components were compared using multivariable logistic regression models to estimate odds ratios (OR) with 95\% confidence intervals (CIs) and were plotted on Kaplan-Meier curves. A multivariable logistic regression model was created to predict cardiac events at the time of repeat CCTA based on age, sex, and all variables that showed a $p$ value $<0.1$ in the univariable analysis. The final model only included variables with a $p$ value $<0.05$ in the initial multivariable model. The selective inclusion of variables helped build a parsimonious model with a small number of variables and meaningful predictability for straightforward clinical implementation. Model fit of the final model was assessed by a Hosmer-Lemeshow-test and Pearson goodness-of-fit test, and the C-statistic was calculated as the discriminatory power of the model.

\section{Results}

A total of 225 patients who underwent CCTA were included. Eighteen patients were excluded due to poor image quality, resulting in a final study population of 197 patients. All patients had DM with mean disease duration of $5.0 \pm 9.7$ years. $47 / 197$ patients (23.9\%) used insulin, and a history of diabetic complications was present in 11 (5.6\%). Eighty-five patients (43.1\%) had hyperlipidemia, and 113 (57.4\%) had hypertension. Sixty patients (30.4\%) had a smoking history. Statins were used by 89 patients (45.2\%). The mean BMI was $25.7 \pm 3.3 \mathrm{~kg} / \mathrm{m}^{2}$. Based on the pretest probability using updated Diamond-forrester methods, there was no difference in the distribution of pretest likelihood of CAD for both groups. Based on the CAD-RADS reporting guideline, the two groups showed insignificant difference in severity of coronary stenosis. Further patient demographics and baseline characteristics are presented in Table 1.

The median time interval between the first and second CCTA was 18.9 months (Q1-Q3, 16.4-32.5 months). The change of plaque characteristics in both patient groups between serial CCTA acquisitions is shown in Table 2. Patients with $\mathrm{CACS} \leq 10$ showed a total mean plaque volume increase of $20.6( \pm 63.5) \mathrm{mm}^{3}$ annually between CCTA scans, resulting in an increase of $2.2 \%$. The CACS $>10$ group demonstrated an average total plaque volume

Table 1 Baseline characteristics and clinical demographics of the study population

\begin{tabular}{|c|c|c|c|}
\hline & All patients $(n=197)$ & Patients with CACS $\leq 10(n=156)$ & Patients with CACS > $10(n=41)$ \\
\hline \multicolumn{4}{|l|}{ Clinical characteristics } \\
\hline Age, years $( \pm S D)$ & $63 \pm 11.4$ & $62.3 \pm 11.3$ & $66.1 \pm 11.1$ \\
\hline Males & $125(63.4 \%)$ & $96(61.5 \%)$ & $29(70.7 \%)$ \\
\hline $\mathrm{BMI}, \mathrm{kg} / \mathrm{m}^{2}( \pm \mathrm{SD})$ & $25.7 \pm 3.3$ & $25.8 \pm 3.4$ & $25.1 \pm 3.1$ \\
\hline Hypercholesterolemia & $85(43 \%)$ & $72(46.1 \%)$ & $13(31.7 \%)$ \\
\hline Hypertension & $113(57.3 \%)$ & $92(58.9 \%)$ & $21(51.2 \%)$ \\
\hline Smoking & $60(30.4 \%)$ & $48(30.7 \%)$ & $12(29.3 \%)$ \\
\hline Family history of CAD & $35(17.8 \%)$ & $26(16.7 \%)$ & $9(21.9 \%)$ \\
\hline Baseline CAC Score & $12.5[0,102.5]$ & $6.5[0,9.8]$ & $29.2[11.3,102.5]$ \\
\hline \multicolumn{4}{|l|}{ Pretest likelihood of CAD } \\
\hline Low & 57 & 45 & 12 \\
\hline Moderate & 111 & 89 & 22 \\
\hline High & 29 & 22 & 7 \\
\hline \multicolumn{4}{|l|}{ Medical therapy } \\
\hline Aspirin & $110(52.7 \%)$ & $82(52.5 \%)$ & $22(53.7 \%)$ \\
\hline Statins & $71(36.0 \%)$ & $53(34.0 \%)$ & $18(43.9 \%)$ \\
\hline B-blocker & $81(41.1 \%)$ & $57(46.5 \%)$ & $24(58.5 \%)$ \\
\hline Calcium channel blocker & 59 (29.9\%) & $46(29.4 \%)$ & $13(31.7 \%)$ \\
\hline \multicolumn{4}{|l|}{ CAD-RADS reporting data } \\
\hline CAD-RADS 0 & 36 & 30 & 7 \\
\hline CAD-RADS 1 & 51 & 41 & 13 \\
\hline CAD-RADS 2 & 100 & 77 & 19 \\
\hline CAD-RADS 3 & 10 & 8 & 2 \\
\hline
\end{tabular}

Values are shown as numbers with percentages in parentheses or mean values with standard deviation 
increase of $30.1( \pm 102.6) \mathrm{mm}^{3}$ annually between acquisitions, corresponding to an increase of $3 \%$. Comparing the increase of total plaque volume between each group showed a significantly larger increase in the CACS $>10$ group $(p=0.002)$. There was no statistically significant difference regarding the percent change of atheroma volume between the two groups $(p=0.676)$, with calculated increases of $5.7 \%( \pm 3.9)$ and $4.2 \%( \pm 3.6)$ in $\mathrm{CACS} \leq 10$ group and CACS $>10$ group, respectively.

The CACS $>10$ group showed a mean increase in dense calcium volume of $5.7( \pm 28.5) \mathrm{mm}^{3}(23 \%)$ over baseline, whereas the dense calcium mean volume increased by $0.3( \pm 13.6) \mathrm{mm}^{3}$ in the group with CACS $\leq 10$, corresponding to an increase of $4.1 \%$. The larger increase in dense calcium volume in the CACS> 10 group was statistically significant when compared to the CACS $\leq 10$ group $(p=0.029)$. Between acquisitions, the average volume of plaque with low "soft", "lipid-rich" attenuation values (i.e., $-100 \mathrm{HU}-30 \mathrm{HU}$ ), increased by $14.3( \pm 34.9) \mathrm{mm}^{3}$ in the CACS $\leq 10$ group, corresponding to an increase of $3.6 \%( \pm 7.9)$ by percent atheroma volume. In patients with CACS $>10$, the mean low attenuation plaque volume increased by $10.9( \pm 34.1) \mathrm{mm}^{3}$, corresponding to an increase of $1.8 \%( \pm 7.4)$ by percent atheroma volume. Significant differences between the groups regarding the change of mean low attenuation plaque volumes were observed $(p=0.018)$; however, there was no significant difference regarding the percent change of atheroma volume $(p>0.05)$.

The comparison of both groups showed a significant difference in the change of average total intermediate attenuation (i.e., $>30 \mathrm{HU}-350 \mathrm{HU})$ "fibrotic" volume $(p=0.018)$, but no significant difference in percent change of atheroma volume $(p>0.05)$.

\section{Analysis of features of plaque vulnerability}

Twenty plaques with at least 2 previously described biomarkers of plaque vulnerability were identified at baseline CCTA (12 in the CACS $\leq 10$ group and 8 in the CACS $>10$ group), while 29 plaques with vulnerable morphology were identified at follow-up CCTA (18 in the $C A C S \leq 10$ group and 11 in the $C A C S>10$ group). Case examples of the progression in the prevalence of plaque features of vulnerability are illustrated in Figs. 2 and 3 . There was no statistically significant difference on the effects of coronary calcification on the rate of vulnerable plaque characteristics $(p>0.05)$.

\section{Follow-up analysis}

Follow-up was completed for all patients included in the study, with a median follow-up time of 41.8 months (Q1-Q3: 32.9-46.1 months). A total of 20 adverse cardiac events occurred (2 cardiac deaths, 15 non-fatal myocardial infarctions and 3 revascularizations). Within a follow-up period of 3 years, only 3 cardiovascular events occurred in subjects with CACS $>10$, corresponding to an overall event-free survival rate of $98.8 \%$. The majority of events $(n=17)$ occurred in subjects with $\mathrm{CACS} \leq 10$. Event-free survival curves for patients in both groups are shown in Fig. 4. The cumulative event-free survival rates were 95\% in patients with CACS $>10$ and $81 \%$ in those with CACS $\leq 10(\log -\operatorname{rank} p=0.025)$.

The final multivariable logistic predictive models are presented in Table 3. The final model included the

Table 2 Change in coronary plaque composition over serial CCTA

\begin{tabular}{|c|c|c|c|c|c|c|c|}
\hline \multirow{2}{*}{$\begin{array}{l}\text { Patients ( } n= \\
\text { 197) }\end{array}$} & \multicolumn{3}{|c|}{ Patients with CACS $\leq 10$} & \multicolumn{3}{|c|}{ Patients with CACS > 10} & \multirow{2}{*}{$\begin{array}{l}P \\
\text { value }\end{array}$} \\
\hline & Baseline & Repeat & $\Delta$-Value & Baseline & Repeat & $\Delta$-Value & \\
\hline Total lumen vol. & $125.5( \pm 113.7)$ & $125.48( \pm 107.0)$ & $2.95( \pm 67.8)$ & $182.3( \pm 131.8)$ & $194.0( \pm 141.8)$ & $10.8( \pm 110.3)$ & 0.060 \\
\hline Total plaque vol. & $85.8( \pm 89.4)$ & $104.4( \pm 106.5)$ & $20.6( \pm 63.5)$ & $102.1( \pm 83.4)$ & $132.1( \pm 116.5)$ & $30.1( \pm 102.6)$ & 0.002 \\
\hline $\mathrm{PAV}, \%( \pm \mathrm{SD})$ & $39.3( \pm 16.4)$ & $44.0( \pm 16.4)$ & $5.7( \pm 13.9)$ & $34.7( \pm 12.8)$ & $38.9( \pm 12.7)$ & $4.2( \pm 13.6)$ & 0.676 \\
\hline \multicolumn{8}{|c|}{ Total dense calcium } \\
\hline Mean $( \pm S D)$ & $6.7( \pm 18.9)$ & $6.8( \pm 16.4)$ & $0.3( \pm 13.6)$ & $23.1( \pm 28.0)$ & $28.8( \pm 35.9)$ & $5.7( \pm 28.5)$ & 0.002 \\
\hline Median [IQR] & $0[0,5.2]$ & $0[0,8.2]$ & $0[0,2.5]$ & $12.2[6.5,28.0]$ & $17.2[7.6,31.1]$ & $1.43[-0.81,4.11]$ & 0.387 \\
\hline $\mathrm{PAV}, \%( \pm \mathrm{SD})$ & $2.5( \pm 4.5)$ & $3.0( \pm 5.2)$ & $0.6( \pm 2.5)$ & $8.0( \pm 7.5)$ & $9.1( \pm 8.8)$ & $1.1( \pm 4.4)$ & 0.360 \\
\hline \multicolumn{8}{|l|}{ Total fibrotic vol. } \\
\hline Mean $( \pm \mathrm{SD})$ & $63.5( \pm 61.9)$ & $71.1( \pm 63.0)$ & $9.2( \pm 40.6)$ & $65.1( \pm 49.5)$ & $77.8( \pm 62.9)$ & $12.6( \pm 53.3)$ & 0.029 \\
\hline $\mathrm{PAV}, \%( \pm \mathrm{SD})$ & $30.9( \pm 14.2)$ & $31.7( \pm 13.0)$ & $0.9( \pm 12.9)$ & $22.9( \pm 10.5)$ & $23.7( \pm 11.3)$ & $0.7( \pm 10.7)$ & 0.70 \\
\hline \multicolumn{8}{|c|}{ Total low attenuation vol. } \\
\hline Mean $( \pm \mathrm{SD})$ & $15.9( \pm 25.9)$ & $29.7( \pm 49.6)$ & $14.3( \pm 34.9)$ & $14.6( \pm 20.9)$ & $25.5( \pm 35.0)$ & $10.9( \pm 34.1)$ & 0.018 \\
\hline PAV, \% ( $\pm \mathrm{SD})$ & $6.7( \pm 7.9)$ & $10.2( \pm 10.0)$ & $3.6( \pm 7.9)$ & $4.3( \pm 4.7)$ & $6.2( \pm 6.6)$ & $1.8( \pm 7.4)$ & 0.850 \\
\hline
\end{tabular}

Continuous variables are presented as mean ( $(\mathrm{SD})$ and median $[\mathrm{IQR}]$ for the dense calcium volume. Percent Atheroma Volume (PAV) is presented as percentages. Volumes (Vol.) are measured in $\mathrm{mm}^{3}$. Differences between delta $(\Delta)$ values were tested with a student's t-test $(p)$ in normal distributed variables and in nonnormal distributed variables with the non-parametric Kruskal-Wallis test $\left(p^{*}\right)$ 

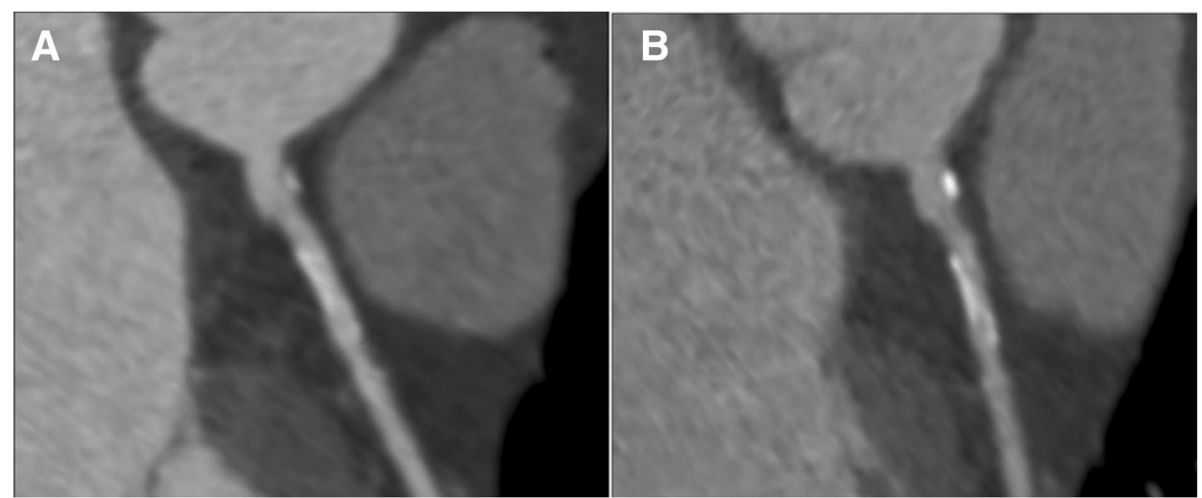

Fig. 2 Example of coronary calcification progression at serial coronary computed tomography angiography. Automatically generated curved multiplanar reformation of image data of the left anterior descending coronary artery in an asymptomatic diabetic 60-year-old man performed in May 2011 (a) and in December 2013 (b). There is progression of dense calcification as well as overall plaque volume, while the stenosis of the coronary artery showed no obvious worsening

presence of CACS $>10$ at the time of repeat CCTA $(\mathrm{ad}-$ justed odds ratio [OR], 0.701; 95\% CI, 0.612-0.836), the increase in dense calcium volume (OR, $0.86095 \%$ CI, 0.771-0.960), and the increase in "soft", "lipid-rich" low attenuation plaque volume (OR, 1.013; 95\% CI, 1.007-1.020) between the two CCTA scans. The model demonstrated good discriminatory power (C-statistic, 0.74 ) with a Hosmer-Lemeshow $\chi^{2}$ statistic of 1.94 ( $p$ value for lack of fit $p=0.75$ ) and Pearson $\chi^{2}$ of 3.29 ( $p$ value for lack of fit $p=0.51$. The bootstrapped C-statistic was 0.73 and the overfitting bias was $0.8 \%$.

\section{Discussion}

Our results showed that in our population of diabetics the change in calcium volume was inversely related to adverse cardiac outcomes. Additionally, the study results indicated that the low attenuation "lipid-rich", soft plaque volume serves as an independent biomarker for predicting future cardiac events, progression of which was positively associated with adverse outcomes during follow-up. It has been argued that the plaque component exhibiting low-attenuation "lipid-rich" features as determined by CT to some extent represents the necrotic core of "vulnerable" atheromatous lesions [21]. Lastly, patients with a CACS $>10$ included in the study demonstrated a higher cumulative event-free survival rate compared to patients with a $C A C S \leq 10$.

The relationship between atherosclerotic plaque progression and cardiovascular risk in asymptomatic diabetic patients is insufficiently studied. Baseline CCTA demonstrated a moderate prevalence of coronary plaque burden (65\%) in the study population, while patients with obstructive CAD at baseline were excluded from further analysis. During the follow-up CT scan, plaque quantification yielded different plaque progression patterns in the study subgroups. Specifically, using a median interval time of
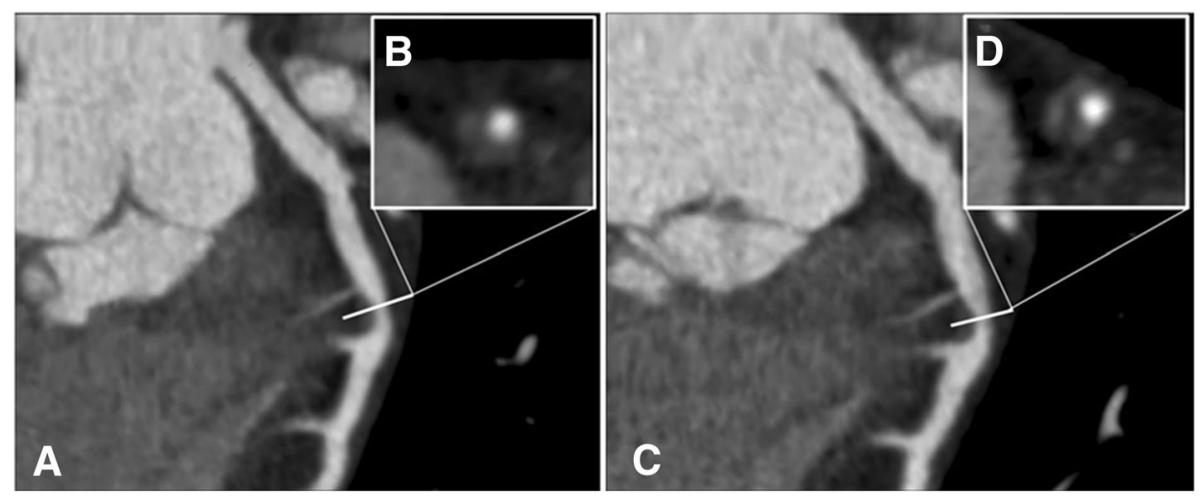

Fig. 3 Example of non-calcified plaque progression at serial coronary computed tomography angiography. Automatically generated curved multiplanar reformation of image data of the left anterior descending coronary artery in an asymptomatic diabetic 46-year-old man performed in December 2010 (a) and in June 2013 (c). Displays of transverse sections perpendicular to the centerline show significant progression of the low-attenuation plaque volume from baseline (b) to follow-up (d) while the degree of coronary artery stenosis at this level worsens 


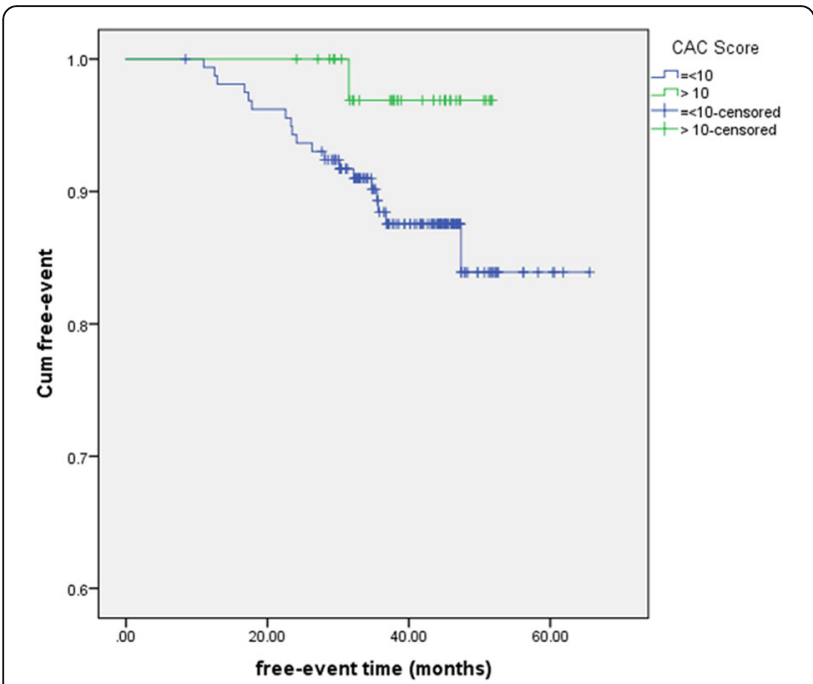

Fig. 4 Event-free survival for the composite endpoint (all-cause mortality, non-fatal myocardial infarction, late revascularization) according to CAC-score

18.9 months between CCTA acquisitions, total plaque volume increased by $20.6 \mathrm{~mm}^{3}$ in the CACS $\leq 10$ group, compared to an increase of $30.1 \mathrm{~mm}^{3}$ in the CACS $>10$ group $(p=0.002)$. This statistically significant difference can be mostly attributed to the increase in total dense calcium volume $\left(0.3 \mathrm{~mm}^{3}\right.$ vs. $\left.5.7 \mathrm{~mm}^{3}, p=0.029\right)$. Furthermore, low-attenuation plaque volume increased by $14.3 \mathrm{~mm}^{3}$ in the $C A C S \leq 10$ group, compared to an increase of 10.9 $\mathrm{mm}^{3}$ in the CACS $>10$ group $(p=0.018)$. This significant increase in low-attenuation plaque volume in participants with $C A C S \leq 10$ corresponded with a higher rate of adverse events in this patient group compared to subjects with CACS $>10$. The more pronounced increase in low-attenuation plaque volume showed independent discriminatory power for the prediction of cardiac events on Cox regression analysis.

Several studies have evaluated the prognostic value of coronary artery calcium, stenosis severity, and cardiac events in diabetic patients. Results from these studies demonstrated an incremental increase in event rates corresponding with increasing calcium Agatston score and stenosis severity $[9,10,22]$. However, these studies failed to evaluate the association between calcification and plaque progression in the early disease stages of asymptomatic diabetics with non-obstructive CAD. Additionally, very few studies using serial CCTA for the evaluation of plaque progression in diabetic patients are available. Kim et al. demonstrated a 2.5 -fold greater progression of total plaque volume during a mean scan interval of 3.8 years in diabetic vs. non-diabetic patient populations. More importantly, the progression of non-calcified plaque volume was significantly greater than that of calcified plaque volume [23]. The significant increase in total plaque volume and the increase of low-attenuation plaque material as a possible marker of necrotic core volume in the present study confirm these previous results.

A recent study focusing on the coronary plaque progression in diabetic patients showed that the baseline percentile of plaque volume and male sex were predictors of progression, but not the coronary calcification [23]. However, in present study the greater increase in low-attenuation plaque in the CACS $\leq 10$ group corresponded with a higher incidence of high-risk plaque features and eventual adverse cardiac events. The CACS $>10$ group showed a significantly greater progression in total plaque volume, which was mainly due to the increase in total dense calcium. The discrepancy between higher calcium progression and lower cardiac event rates may be explained by plaque stabilization under statin therapy [24]. On a histo-pathologic level,

Table 3 Multivariate Logistic regression models for prediction of cardiac events

\begin{tabular}{|c|c|c|c|c|c|c|}
\hline \multirow[t]{2}{*}{ Variables } & \multicolumn{3}{|c|}{ Initial Model } & \multicolumn{3}{|c|}{ Final Model } \\
\hline & $\mathrm{OR}$ & $p$ value & $95 \% \mathrm{Cl}$ & OR & $p$ value & $95 \% \mathrm{Cl}$ \\
\hline$\overline{\text { Age }}$ & 1.036 & 0.202 & $0.981-1.095$ & $\ldots$ & $\ldots$ & $\ldots$ \\
\hline Male sex & 1.825 & 0.343 & $0.527-6.322$ & $\ldots$ & $\ldots$ & $\ldots$ \\
\hline Hypertension & 2.786 & 0.130 & $0.738-10.511$ & & $\ldots$ & $\ldots$ \\
\hline Dyslipidemia & 1.687 & 0.362 & $0.548-5.198$ & $\ldots$ & $\ldots$ & $\ldots$ \\
\hline tobacco abuse & 1.240 & 0.771 & $0.291-5.282$ & $\ldots$ & $\ldots$ & $\ldots$ \\
\hline Family history CAD & 3.353 & 0.063 & $0.936-12.013$ & $\ldots$ & $\ldots$ & $\ldots$ \\
\hline CAC score $>10$ & 0.554 & 0.017 & $0.505-0.589$ & 0.701 & 0.034 & $0.612-0.836$ \\
\hline Calcium Vol. change & 0.804 & 0.004 & $0.693-0.933$ & 0.860 & 0.007 & $0.771-0.960$ \\
\hline Fibrotic Vol. Change & 1.002 & 0.928 & $0.969-1.035$ & $\ldots$ & $\ldots$ & $\ldots$ \\
\hline Lipid Vol. Change & 1.016 & 0.009 & $1.004-1.027$ & 1.013 & $<0.001$ & $1.007-1.020$ \\
\hline Total Plaque Change & 1.000 & 0.969 & $0.977-1.025$ & $\ldots$ & $\ldots$ & $\ldots$ \\
\hline
\end{tabular}


asymptomatic patients with diabetes usually exhibit chronic endothelial damage and local factors that promote progressive atherosclerosis. These factors in conjunction with glycated protein oxidation could accelerate the calcification process, leading to spotty calcification associated with plaque vulnerability [25]. The present study illustrated a greater progression of spotty calcifications in patients with CACS $\leq 10$ than in patients with CACS $>10$ while it appears conceivable that dense calcification may stabilize the plaque with a decrease in necrotic core burden and frequency of cardiac events.

Although CCTA can be a useful tool for risk stratification in diabetic patients with at least 5 years of asymptomatic CAD [26], it requires further investigation to determine whether the progression of plaque burden can be used for personalized treatment guidance and surveillance, especially in patients with high cardiovascular risk. Using serial CCTA acquisitions, our investigation demonstrated the feasibility of quantifying plaque progression and identified several imaging biomarkers that may have a positive or inverse association with future cardiac events in asymptomatic diabetics. Conceivably, repeat CCTA at an intermediate time-point after the initiation of optimized medical therapy may inform granular custom-tailoring of the treatment regimen based on the individual progression pattern of the coronary plaque burden. Although current Appropriate Use Criteria for Cardiac Computed Tomography do not incorporate prior CCTA results [27], the value of serial CCTA may warrant more consideration, especially for asymptomatic diabetic patients at high risk who may benefit from personalized risk stratification and modification of optimized medical therapy [28].

Several limitations to the present study deserve consideration. This is a single-center retrospective investigation with a patient population representing a single ethnicity, with potential bias due to selection and test power. It is possible that the prevalence and disease course of CAD could be influenced by the patient population's ethnicity or other geographical factors. Furthermore, we did not systematically correlate our findings on coronary CTA with an invasive reference standard for intracoronary plaque assessment. Although the plaque software prototype has been validated in several studies $[13,29]$, there might be variation among different automated plaque quantification software. Thus, the same software should be used for serial assessment. Likewise, plaque quantification might be affected by technical influences, e.g. by the attenuation level of vascular contrast enhancement [30]. Moreover, the present study lacked of medication details in treating diabetes. New advanced treatment like incretin (GLP-1) therapy may play an important role in preventing plaque progression based on its pluripotent cardiovascular protective effects [31]. Also, the potential mechanism, for example the effect of genes' polymorphism in secondary affecting the prognosis in the study population [32], needs to be further investigated. Therefore, these results may be applicable to very specific population, and prospective studies on larger study cohorts will be necessary to validate our findings.

\section{Conclusions}

This investigation demonstrates that quantification of plaque progression derived from non-invasive serial CCTA portends incremental prognostic value, with low-attenuation "lipid-rich" atheromatous plaque volume showing the highest predictive value. Meanwhile, an increase of dense coronary artery calcification is inversely correlated with the progression of low-attenuation plaque burden, arguably reflecting the role of the pathophysiology of calcification on plaque stabilization during coronary atherosclerosis in diabetes. Granular serial evaluation of atheromatous plaque progression patterns may benefit asymptomatic diabetic patients via personalized risk re-stratification and subsequent adjustment of optimized medical therapy.

\section{Abbreviations \\ BMI: Body mass index; CACS: Coronary artery calcium score; CAD: Coronary artery disease; CCTA: Coronary CT angiography; Cl: Confidence interval; DM: Diabetes mellitus; DSCT: Dual-source CT; MACE: Major adverse cardiac event; OR: Odds ratio; PVI: Plaque volume index; SD: Standard deviation \\ Acknowledgements \\ The authors thank Ron Blankstein, MD for comments that greatly improved the manuscript. \\ Funding \\ The design of the study, collection and analysis of data were supported by grants from The National Key Research and development program of China (2016YFC1300304), the Beijing NOVA Program (Z181110006218055) and Capital Special Clinical Application Grants (Z141107002514103).}

\section{Availability of data and materials}

The datasets used and/or analysed during the current study are available from the corresponding author on reasonable request.

\section{Authors' contributions}

$J Y, G D$ and $C T$ analyzed and interpreted the patient data regarding the coronary plaque analysis. JY and GD performed phone call follow-up for the cardiovascular events and were major contributors in writing the manuscript. $C D, B J$, US and YC participate in the study design and protocol revision. All authors agreed to be accountable for all aspects of the work in ensuring that questions related to the accuracy or integrity of any part of the work are appropriately investigated and resolved.

\section{Ethics approval and consent to participate}

Approved by the Institutional Review Board of Chinese PLA general hospital with a waiver of informed consent due to the retrospective nature of this investigation.

\section{Consent for publication}

Not applicable.

\section{Competing interests}

Dr. Schoepf receives institutional research support from Astellas, Bayer, GE, Medrad, and Siemens. Dr. Schoepf has received consulting fees from Bayer and Guerbet. Dr. De Cecco receives institutional research support from 
Siemens and has received consulting fees from Guerbet. Christian Tesche is an exchange visiting scholar supported by a grant from the Fulbright Visiting Scholar Program of the U.S. Department of State, Bureau of Educational and Cultural Affairs (ECA). The other authors declare that they have no competing interests.

\section{Publisher's Note}

Springer Nature remains neutral with regard to jurisdictional claims in published maps and institutional affiliations.

\section{Author details}

'Department of Cardiology, Chinese PLA General Hospital, Beijing, People's Republic of China. ${ }^{2}$ Master Program of Medical Science and Clinical Investigation, Harvard Medical School, Boston, MA, USA. ${ }^{3}$ Division of Cardiovascular Imaging, Department of Radiology and Radiological Science, Medical University of South Carolina, Charleston, SC, USA. ${ }^{4}$ Department of Cardiology and Intensive Care Medicine, Heart Center Munich- Bogenhausen, Munich, Germany.

Received: 28 June 2018 Accepted: 4 February 2019 Published online: 11 February 2019

\section{References}

1. Emerging Risk Factors C, Sarwar N, Gao P, Seshasai SR, Gobin R, Kaptoge S, Di Angelantonio E, Ingelsson E, Lawlor DA, Selvin E, et al. Diabetes mellitus, fasting blood glucose concentration, and risk of vascular disease: a collaborative meta-analysis of 102 prospective studies. Lancet. 2010; 375(9733):2215-22.

2. Perk J, De Backer G, Gohlke H, Graham I, Reiner Z, Verschuren M, Albus C, Benlian P, Boysen G, Cifkova R, et al. European guidelines on cardiovascular disease prevention in clinical practice (version 2012). The fifth joint task force of the European Society of Cardiology and Other Societies on cardiovascular disease prevention in clinical practice (constituted by representatives of nine societies and by invited experts). Eur Heart J. 2012; 33(13):1635-701.

3. Farkou ME. ACP journal Club. Review: Diabetes is not a coronary disease equivalent. Ann Intern Med. 2009;151(4):JC2-6-7.

4. Zellweger MJ, Hachamovitch R, Kang X, Hayes SW, Friedman JD, Germano $G$, Pfisterer ME, Berman DS. Prognostic relevance of symptoms versus objective evidence of coronary artery disease in diabetic patients. Eur Heart J. 2004;25(7):543-50.

5. American Diabetes A. Standards of medical care in diabetes--2013. Diabetes Care. 2013;36(Suppl 1):S11-66.

6. Young LH, Wackers FJ, Chyun DA, Davey JA, Barrett EJ, Taillefer R, Heller GV, Iskandrian AE, Wittlin SD, Filipchuk N, et al. Cardiac outcomes after screening for asymptomatic coronary artery disease in patients with type 2 diabetes: the DIAD study: a randomized controlled trial. JAMA. 2009:301(15):1547-55.

7. Kwan AC, May HT, Cater G, Sibley CT, Rosen BD, Lima JA, Rodriguez K, Lappe DL, Muhlestein JB, Anderson JL, et al. Coronary artery plaque volume and obesity in patients with diabetes: the factor-64 study. Radiology. 2014; 272(3):690-9.

8. Zellweger MJ, Maraun M, Osterhues HH, Keller U, Muller-Brand J, Jeger R, Pfister O, Burkard T, Eckstein F, von Felten S, et al. Progression to overt or silent CAD in asymptomatic patients with diabetes mellitus at high coronary risk: main findings of the prospective multicenter BARDOT trial with a pilot randomized treatment substudy. J Am Coll Cardiol Img. 2014; 7(10):1001-10

9. van den Hoogen IJ, de Graaf MA, Roos CJ, Leen AC, Kharagjitsingh AV Wolterbeek R, Kroft LJ, Wouter Jukema J, Bax JJ, Scholte AJ. Prognostic value of coronary computed tomography angiography in diabetic patients without chest pain syndrome. J Nucl Cardiol. 2016;23(1):24-36.

10. Kramer CK, Zinman B, Gross JL, Canani LH, Rodrigues TC, Azevedo MJ, Retnakaran R. Coronary artery calcium score prediction of all cause mortality and cardiovascular events in people with type 2 diabetes: systematic review and meta-analysis. BMJ. 2013;346:f1654.

11. Bauer RW, Thilo C, Chiaramida SA, Vogl TJ, Costello P, Schoepf UJ. Noncalcified atherosclerotic plaque burden at coronary CT angiography: a better predictor of ischemia at stress myocardial perfusion imaging than calcium score and stenosis severity. AJR Am J Roentgenol. 2009; 193(2):410-8

12. Tesche C, De Cecco CN, Caruso D, Baumann S, Renker M, Mangold S, Dyer KT, Varga-Szemes A, Baquet M, Jochheim D, et al. Coronary CT angiography derived morphological and functional quantitative plaque markers correlated with invasive fractional flow reserve for detecting hemodynamically significant stenosis. J Cardiovasc Comput Tomogr. 2016;10(3):199-206.

13. Tesche C, Plank F, De Cecco CN, Duguay TM, Albrecht MH, VargaSzemes A, Bayer RRN, Yang J, Jacks IL, Gramer BM, et al. Prognostic implications of coronary CT angiography-derived quantitative markers for the prediction of major adverse cardiac events. J Cardiovasc Comput Tomogr. 2016;10(6):458-65

14. Ito H, Motoyama S, Sarai M, Kawai H, Harigaya H, Kan S, Kato S, Anno $\mathrm{H}$, Takahashi $\mathrm{H}$, Naruse $\mathrm{H}$, et al. Characteristics of plaque progression detected by serial coronary computed tomography angiography. Heart Vessel. 2014;29(6):743-9.

15. Oberoi S, Meinel FG, Schoepf UJ, Nance JW, De Cecco CN, Gebregziabher M, Costello P, Weininger M. Reproducibility of noncalcified coronary artery plaque burden quantification from coronary $C T$ angiography across different image analysis platforms. AJR Am J Roentgenol. 2014;202(1):W43-9.

16. Blackmon KN, Streck J, Thilo C, Bastarrika G, Costello P, Schoepf UJ. Reproducibility of automated noncalcified coronary artery plaque burden assessment at coronary CT angiography. J Thorac Imaging. 2009;24(2):96-102.

17. Nadjiri J, Hausleiter J, Jahnichen C, Will A, Hendrich E, Martinoff S, Hadamitzky M. Incremental prognostic value of quantitative plaque assessment in coronary CT angiography during 5 years of follow up. J Cardiovasc Comput Tomogr. 2016;10(2):97-104.

18. Gu H, Gao Y, Wang H, Hou Z, Han L, Wang X, Lu B. Sex differences in coronary atherosclerosis progression and major adverse cardiac events in patients with suspected coronary artery disease. J Cardiovasc Comput Tomogr. 2017;11(5):367-72.

19. Elkeles RS, Godsland IF, Feher MD, Rubens MB, Roughton M, Nugara F, Humphries SE, Richmond W, Flather MD, Group PS. Coronary calcium measurement improves prediction of cardiovascular events in asymptomatic patients with type 2 diabetes: the PREDICT study. Eur Heart J. 2008;29(18):2244-51.

20. Cury RC, Abbara S, Achenbach S, Agatston A, Berman DS, Budoff MJ, Dill KE, Jacobs JE, Maroules CD, Rubin GD, et al. Coronary artery disease - reporting and data system (CAD-RADS): an expert consensus document of SCCT, ACR and NASCl: endorsed by the ACC. J Am Coll Cardiol Img. 2016;9(9):1099-113.

21. Benedek T, Gyongyosi M, Benedek I. Multislice computed tomographic coronary angiography for quantitative assessment of culprit lesions in acute coronary syndromes. Can J Cardiol. 2013;29(3):364-71.

22. Agarwal S, Cox AJ, Herrington DM, Jorgensen NW, Xu J, Freedman BI, Carr $J$ J, Bowden DW. Coronary calcium score predicts cardiovascular mortality in diabetes: diabetes heart study. Diabetes Care. 2013;36(4):972-7.

23. Kim U, Leipsic JA, Sellers SL, Shao M, Blanke P, Hadamitzky M, Kim YJ, Conte $E$, Andreini D, Pontone G, et al. Natural history of diabetic coronary atherosclerosis by quantitative measurement of serial coronary computed tomographic angiography: results of the PARADIGM study (progression of atherosclerotic plaque determined by computed tomographic angiography imaging). J Am Coll Cardiol Img. 2018;11(10):1461-71.

24. Banach M, Serban C, Sahebkar A, Mikhailidis DP, Ursoniu S, Ray KK, Rysz J, Toth PP, Muntner P, Mosteoru S, et al. Impact of statin therapy on coronary plaque composition: a systematic review and meta-analysis of virtual histology intravascular ultrasound studies. BMC Med. 2015;13:229.

25. McCullough PA, Fazel P, Choi JW. Screening, diagnosis, and management of CAD in asymptomatic diabetic patients. J Am Coll Cardiol Img. 2014;7(10):1011-2.

26. Hadamitzky M, Taubert S, Deseive S, Byrne RA, Martinoff S, Schomig A, Hausleiter J. Prognostic value of coronary computed tomography angiography during 5 years of follow-up in patients with suspected coronary artery disease. Eur Heart J. 2013;34(42):3277-85.

27. Taylor AJ, Cerqueira M, Hodgson JM, Mark D, Min J, O'Gara P, Rubin GD, American College of Cardiology Foundation Appropriate Use Criteria Task F, Society of Cardiovascular Computed T, American College of $\mathrm{R}$, et al. ACCF/SCCT/ACR/AHA/ASE/ASNC/NASCI/SCAI/SCMR 2010 Appropriate use criteria for cardiac computed tomography. A report of the American College of Cardiology Foundation appropriate use criteria 
task force, the Society of Cardiovascular Computed Tomography, the American College of Radiology, the American Heart Association, the American Society of Echocardiography, the American Society of Nuclear Cardiology, the north American Society for Cardiovascular Imaging, the Society for Cardiovascular Angiography and Interventions, and the Society for Cardiovascular Magnetic Resonance. Circulation. 2010;122(21):e525-55.

28. Kumamaru KK, Kondo T, Kumamaru H, Amanuma M, George E, Rybicki FJ. Repeat coronary computed tomographic angiography in patients with a prior scan excluding significant stenosis. Circ Cardiovasc Imaging. 2014;7(5):788-95.

29. Tesche C, De Cecco CN, Vliegenthart R, Duguay TM, Stubenrauch AC, Rosenberg RD, Varga-Szemes A, Bayer RR 2nd, Yang J, Ebersberger U, et al. Coronary $\mathrm{CT}$ angiography-derived quantitative markers for predicting in-stent restenosis. J Cardiovasc Comput Tomogr. 2016;10(5):377-83.

30. Henzler T, Porubsky S, Kayed H, Harder N, Krissak UR, Meyer M, Sueselbeck T, Marx A, Michaely H, Schoepf UJ, et al. Attenuation-based characterization of coronary atherosclerotic plaque: comparison of dual source and dual energy $\mathrm{CT}$ with single-source $\mathrm{CT}$ and histopathology. Eur J Radiol. 2011;80(1):54-9.

31. Marfella R, Sardu C, Balestrieri ML, Siniscalchi M, Minicucci F, Signoriello G, Calabro P, Mauro C, Pieretti G, Coppola A, et al. Effects of incretin treatment on cardiovascular outcomes in diabetic STEMI-patients with culprit obstructive and multivessel non obstructive-coronary-stenosis. Diabetol Metab Syndr. 2018;10:1.

32. Balestrieri ML, Rizzo MR, Barbieri M, Paolisso P, D'Onofrio N, Giovane A, Siniscalchi M, Minicucci F, Sardu C, D'Andrea D, et al. Sirtuin 6 expression and inflammatory activity in diabetic atherosclerotic plaques: effects of incretin treatment. Diabetes. 2015:64(4):1395-406.

Ready to submit your research? Choose BMC and benefit from:

- fast, convenient online submission

- thorough peer review by experienced researchers in your field

- rapid publication on acceptance

- support for research data, including large and complex data types

- gold Open Access which fosters wider collaboration and increased citations

- maximum visibility for your research: over $100 \mathrm{M}$ website views per year

At $\mathrm{BMC}$, research is always in progress.

Learn more biomedcentral.com/submissions 